\title{
Buprenorphine Depresses Respiratory Variability in Obese Mice with Altered Leptin Signaling
}

\author{
Chelsea Angel, B.A. ${ }^{1}$, Zachary T. Glovak, B.A. ${ }^{1,2}$, Wateen Alami, B.A. ${ }^{1}$, Sara Mihalko, B.A. ${ }^{1}$, \\ Josh Price, M.S. ${ }^{3}$, Yandong Jiang, M.D., Ph.D. ${ }^{5}$, Helen A. Baghdoyan, Ph.D. ${ }^{1,2,4}$, and Ralph \\ Lydic, Ph.D. ${ }^{1,2,4}$ \\ ${ }^{1}$ Department of Anesthesiology, University of Tennessee, Knoxville, TN \\ 2Department of Psychology, University of Tennessee, Knoxville, TN \\ ${ }^{3}$ Department of Information Technology, University of Tennessee, Knoxville, TN \\ ${ }^{4}$ Oak Ridge National Laboratory, Oak Ridge, TN \\ ${ }^{5}$ Department of Anesthesiology, Vanderbilt University, Nashville, TN
}

\begin{abstract}
Background-Opiate-induced respiratory depression is sexually dimorphic and associated with increased risk among the obese. The mechanisms underlying these associations are unknown. The present study evaluated the two-tailed hypothesis that sex, leptin status, and obesity modulate buprenorphine-induced changes in breathing.
\end{abstract}

Methods-Mice ( $\mathrm{n}=40$ male and 40 female) comprising four congenic lines that differ in leptin signaling and body weight were injected with saline and buprenorphine $(0.3 \mathrm{mg} / \mathrm{kg})$. Whole body plethysmography was used to quantify the effects on minute ventilation. Data were evaluated using three-way analysis of variance, regression, and Poincaré analyses.

Results-Relative to B6 mice with normal leptin, buprenorphine decreased minute ventilation in mice with diet-induced obesity (37.2\%; $\mathrm{P}<0.0001)$, ob/ob mice that lack leptin (62.6\%; $\mathrm{P}$ $<0.0001)$, and $\mathrm{db} / \mathrm{db}$ mice with dysfunctional leptin receptors $(65.9 \% ; \mathrm{P}<0.0001)$. Poincaré analyses showed that buprenorphine caused a significant $(P<0.0001)$ collapse in minute ventilation variability that was greatest in mice with leptin dysfunction. There was no significant effect of sex or body weight on minute ventilation.

Conclusions-The results support the interpretation that leptin status but not body weight or sex contributed to the buprenorphine-induced decrease in minute ventilation. Poincaré plots illustrate that the buprenorphine-induced decrease in minute ventilation variability was greatest in mice with impaired leptin signaling. This is relevant because normal respiratory variability is essential for

Corresponding Author: Ralph Lydic, Ph.D., Departments of Anesthesiology and Psychology, University of Tennessee, Knoxville, TN 37996 U.S.A., rlydic@utk.edu, Voice: (734) 546-4921, FAX: (865) 305-6338.

Prior Presentations: Preliminary results have been presented. American Physiological Society Conference: Cardiovascular, Renal and Metabolic Diseases-Physiology and Gender, 18 Nov 2015 Annapolis, MD, and Experimental Biology, 3 April 2016, San Diego, CA. 
martialing a compensatory response to ventilatory challenges imposed by disease, obesity, and surgical stress.

This study was motivated by two imperatives. First, the ongoing epidemics of opiate abuse ${ }^{1}$ and obesity ${ }^{2}$ reinforce our interest in opiate research with potential for translational relevance. ${ }^{3-12}$ Second, opiate-induced alterations in the ventilatory response to hypercapnia are sexually dimorphic, ${ }^{13}$ consistent with evidence that respiratory control is altered by sex steroid hormones. ${ }^{14}$ Additional data show that opiate-induced respiratory depression is associated with increased risk among subjects who are female ${ }^{15}$ and/or obese. ${ }^{16}$ There is consensus that gaps in knowledge regarding mechanisms by which opiates alter breathing "warrant further study of the sex-dependent and sex-independent genetic factors", and that "inbred strains of mice and rats may serve as the best model". ${ }^{13}$ We concur, and the present study quantified the effects of buprenorphine on minute ventilation variability in obese and normal weight male and female mice. The obese mice used for this study were characterized by either disrupted leptin signaling or diet-induced obesity. This design made it possible to use a three-way, mixed effects analysis of variance model to evaluate the two-tailed hypothesis that buprenorphine causes breathing to vary significantly due to sex, leptin status, and obesity. Buprenorphine was a logical choice because it is used for pain management in addicted patients ${ }^{17}$ and because it is one of three medications approved for treating opiate use disorder. 1,18

\section{Materials and Methods}

\section{Animals}

Experiments and procedures were reviewed and approved by the University of Tennessee Institutional Animal Care and Use Committee. All phases of the experiments adhered to the Guide for the Care and Use of Laboratory Animals (The National Academies Press, $8^{\text {th }}$ ed., Washington, DC, 2011). Mice had ad libitum access to food and water and were housed under 24-h illumination to promote free-running rhythms and offset potential circadian confounds. ${ }^{10}$ Adult mice ( $\mathrm{n}=80$ ) were purchased from The Jackson Laboratory (Bar Harbor, ME, USA). These congenic mice (10 males and 10 females of each line) included normal weight C57BL/6J (B6) wild-type mice that produce leptin, B6 mice with diet-induced obesity (DIO) that may lead to leptin resistance, obese B6.Cg-Lep ${ }^{\mathrm{ob}} / \mathrm{J}$ mice (ob/ob) that do not make leptin, and B6.BKS(D)-Lepr ${ }^{\mathrm{db}} / \mathrm{J}(\mathrm{db} / \mathrm{db})$ mice that are obese, produce leptin, and lack functional leptin receptors. None of these mice are transgenic animals, and the ob/ob and $\mathrm{db} / \mathrm{db}$ mice were derived from spontaneous mutations in the B6 line. These congenic lines are maintained at the Jackson Laboratory by a multi-generational breeding program that backcrosses a mutation of interest into different mice, thereby transferring the mutations of interest. The B6, ob/ob, and db/db mice were fed normal Teklad 8640 rodent chow comprised of $5 \%$ fat. The DIO mice were fed a $60 \%$ fat diet for 20 weeks prior to and during the testing period. Both rodent chows were purchased from Research Diets, Inc., (New Brunswick, NJ, USA). 


\section{Congenic Mice in Relation to the Experimental Design}

The four congenic lines of mice (B6, DIO, ob/ob, and db/db) are ideally suited to calls for studies "of the sex-dependent and sex-independent genetic factors" 13 contributing to opiateinduced changes in breathing. Efforts to understand the sexually dimorphic response to opiates $^{15,19}$ are scientifically sound ${ }^{20}$ and consistent with the 2016 policy mandating that NIH-funded studies include sex as a biological variable. ${ }^{21}$

Among the four mouse lines, the obesity and leptin phenotypes were regarded as sexindependent factors that may contribute to buprenorphine-induced alterations in breathing. This possibility is suggested by the fact that leptin, produced by adipocytes, covaries with obesity, and modulates breathing ${ }^{22-25}$ and nociception. ${ }^{7,10,12}$ Table 1 summarizes similarities and differences between the obesity and leptin phenotypes in the four congenic mouse lines studied. Use of three-way analysis of variance made it possible to evaluate the effects of buprenorphine on breathing as a function of sex, leptin status, and obesity.

\section{Buprenorphine Administration and Measures of Breathing}

Mice were injected (i.p.) with saline or buprenorphine $(0.3 \mathrm{mg} / \mathrm{kg})$ (Sigma Aldrich, St. Louis, MO, USA). Buprenorphine was dissolved in saline to yield the desired concentration while holding injection volume $(0.3 \mathrm{~mL})$ constant. The $0.3 \mathrm{mg} / \mathrm{kg}$ dose of buprenorphine has been shown to be antinociceptive in $\mathrm{B} 6$ mice $^{26}$ and in males and females of the four congenic mouse lines used in this study. ${ }^{12}$ Before starting data collection, mice were habituated to being placed in whole body plethysmography chambers (Data Sciences International, St. Paul, MN, USA) where they were free to move and groom. After one week of habituation, mice were randomly assigned to receive either saline or buprenorphine injection and were placed in the plethysmography chambers where breathing was automatically recorded for $1 \mathrm{~h}$. Testing occurred at the same time of day and all mice had one week for recovery between injections. Breathing signals from mice in the plethysmography chambers were automatically digitized by the software, circumventing the need to blind experimenters to injection condition (saline vs. buprenorphine). Pioneering studies of rodent breathing across genetic lines ${ }^{27}$ demonstrated that measures must be scaled to body mass, differences in $\mathrm{CO}_{2}$ production, hypoxic and hypercapnic ventilatory responses, dead space, fat distribution, and many other factors. The present measures of the effects of buprenorphine on minute ventilation across four congenic lines of mice were therefore expressed as $\mathrm{mL} / \mathrm{min} / \mathrm{g}$ body weight, consistent with our previous studies on the respiratory effects of isoflurane ${ }^{28}$ and sedative/hypnotics. ${ }^{29}$

\section{Statistical Analyses}

Sample sizes ( $\mathrm{n}=80$ mice consisting of 10 males and 10 females representing each of the four congenic mouse lines) were based on previous experience. ${ }^{7,10,12,29}$ The data were analyzed with Statistical Analysis System v9.4TS1M3 (SAS Institute, Inc., Cary, NC), using a three-way mixed effects, repeated measures analysis of variance (ANOVA) model with two between subject factors (sex and mouse line) and one within subject factor of injection condition (saline vs. buprenorphine). Mouse nested within sex by mouse line was included as a random effect. After a log transformation was applied to minute ventilation values, the data satisfied all assumptions of the ANOVA model including normal distribution of 
residuals, similar variances, and no major outliers. No other transformations were required. Bonferroni adjustment was used to correct the $P$-values for all post-hoc comparisons.

\section{Poincaré as Exploratory Data Analysis}

Poincaré analysis is well established and permits novel diagnostic and prognostic insights. ${ }^{30}$ The heuristic value of Poincaré analysis also makes it clinically relevant for diverse disorders ranging from locomotion ${ }^{31}$ to sleep. ${ }^{32}$ Poincaré analysis can even help identify phenotypes of metabolic syndrome. ${ }^{33}$ Relative to anesthesiology, Poincaré analysis has been used as a weaning predictor for some postoperative patients, ${ }^{34}$ for estimating levels of sedation-analgesia, ${ }^{35}$ and to characterize anesthesia-induced changes in electroencephalogram. ${ }^{36}$

By plotting a dependent measure relative to the previous dependent measure, Poincaré analysis makes it possible to quantify and visualize variability within a data set. ${ }^{30}$ The resulting dispersion of points conveys novel information about variability in the data (fig. 1). For the present study, Poincaré analysis was used to characterize how buprenorphine alters the variability of minute ventilation. Whole body plethysmography data were averaged every $5 \mathrm{~min}$ for $1 \mathrm{~h}$. Poincaré analysis was used to quantify respiratory variability among male and female B6, DIO, ob/ob, and db/db mice in response to injection of saline and buprenorphine. Points in the Poincaré plots of minute ventilation represent time intervals of an inspiratory and expiratory cycle. In the present study, Poincaré short-term variability (SD1) quantified the variation in breathing during the 5 min measurement intervals. Long-term variability (SD2) quantified the overall variability in breathing throughout the $1 \mathrm{~h}$ measurement period. SD1 describes more rapid changes and SD2 describes long-term changes. Short-term variability (SD1) also is described by the standard deviation of successive differences (SDSD) in a breath-to-breath cycle, and long-term variability (SD2) also can be described by the standard deviation in breath-to-breath intervals (SDBB). ${ }^{37}$ Both analytic approaches were applied to the present data set.

\section{Results}

Figure 2 shows that DIO, ob/ob, and db/db mice had decreased minute ventilation under the control (saline) condition. Compared to the B6 (wild type) mice, buprenorphine decreased average minute ventilation by $37.2 \%$ in DIO mice $(\mathrm{t}=7.68, \mathrm{df}=72, \mathrm{P}<0.0001), 62.6 \%$ in ob/ob mice ( $\mathrm{t}=16.61, \mathrm{df}=72, \mathrm{P}<0.0001)$, and $65.9 \%$ in $\mathrm{db} / \mathrm{db}$ mice $(\mathrm{t}=18.21, \mathrm{df}=72, \mathrm{P}$ $<0.0001)$. There was no significant sex main-effect on minute ventilation. Regression analyses revealed that in no case did body weight alone account for a significant decrease in minute ventilation.

\section{Buprenorphine Decreased Variability in Minute Ventilation across all Congenic Mouse Lines}

Figure 3 shows Poincaré plots illustrating features of the buprenorphine-induced decrease in minute ventilation variability. The collapse in short-term variability (SD1), visualized in figure 3 as the distribution of points perpendicular to $x=y$, is not apparent in figure 2 . The Poincaré plots show that compared to saline, buprenorphine caused a collapse in minute 
ventilation variability across all four lines of mice. Three-way ANOVA indicated that shortterm variability (SD1) was significantly decreased $(F=45.03 ; d f=3,72 ; P<0.0001)$ as a function of mouse line and injection condition (saline or buprenorphine) $(F=148.98 ; d f=$ $1,72 ; P<0.0001)$. The only significant interaction was between mouse line and injection condition $(F=5.30 ; d f=3,72 ; P=0.0023)$. Post-hoc comparisons showed that buprenorphine caused a greater compression of short-term variability of minute ventilation in the DIO, ob/ob, and db/db mice than in the B6 mice. Figure 4 shows that when short-term variability was expressed as the standard deviation of successive differences in breath-tobreath intervals (SDSD), mice with disrupted leptin signaling had lower minute ventilation variability than B6 (wild type) mice.

Long-term variability (SD2) of minute ventilation (fig. 3, dispersion of points along the line $\mathrm{x}=\mathrm{y})$ differed significantly by mouse line $(F=52.66 ; d f=3,72 ; P<0.0001)$, sex $(F=9.05$; $d f=1,72 ; P=0.0036)$, and injection condition $(F=184.42 ; d f=1,72 ; P<0.0001)$. There was a significant $(F=4.02 ; d f=3,72 ; P=0.0105)$ sex by mouse line interaction for longterm changes in variability of minute ventilation. Post-hoc analyses showed that long-term variability in minute ventilation of normal weight $\mathrm{B} 6$ mice differed from that of DIO, ob/ob, and $\mathrm{db} / \mathrm{db}$ mice. Applying three-way ANOVA to long-term variability data calculated as the standard deviation of breath-to-breath intervals (SDBB) revealed similar results (figure 5). Considered together, the results of analyses illustrated by figs. 4 and 5 support the conclusion that buprenorphine caused the greatest decrease in minute ventilation variability in mice with impaired leptin signaling.

\section{Discussion}

Three major findings emerged from this study. First, minute ventilation was significantly altered by leptin status in the absence of buprenorphine. Second, minute ventilation did not vary significantly due to sex. Third, Poincaré plots illustrate that buprenorphine causes a collapse in minute ventilation variability. The findings are discussed below relative to the relationship between leptin and obesity, making the point that studies of congenic mice can provide unique insights into this relationship. Finally, we describe the previously unrecognized effect of buprenorphine to decrease respiratory variability. Limitations of the present study also are addressed.

\section{Leptin, obesity, and murine models of disease}

The perspective that obesity is a disease satisfies multiple criteria, the most stringent of which is the increased risk that obesity conveys for premature death. ${ }^{38,39}$ Analysis of closed claims cases identified obesity as a risk factor for opiate-induced respiratory depression resulting in severe brain damage or death. ${ }^{40}$ Leptin covaries with obesity, making it difficult to quantify the exact degree to which breathing varies as a function of obesity, leptin, or both. The present study confronted this complexity in two ways. First, the experiments were specifically designed to compare the respiratory effects of buprenorphine in normal weight B6 mice possessing normal leptin to the respiratory effects of buprenorphine in three congenic lines of obese mice, each with different obesity/leptin profiles. The four mouse lines made it possible to relate buprenorphine-induced changes in breathing (figs. 2-5) to 
obesity and leptin status (Table 1). B6 mice provided an ideal control group as they are among the lines of healthy mice that The Mouse Phenome Committee recommend receive the highest priority for phenotyping. ${ }^{41} \mathrm{~B} 6$ mice with diet-induced obesity are genetically identical to normal weight B6 mice. DIO mice are homologous to the vast majority of obese humans in that the mice possess both leptin and leptin receptors that, over time, may become leptin resistant. Regression analyses provided a second approach for evaluating the degree to which buprenorphine-induced changes in breathing were altered by obesity or leptin. Those analyses showed that for none of the four mouse lines did body weight account for a significant change in minute ventilation. This finding is consistent with evidence that body weight alone does not significantly alter the anti-nociceptive effects of buprenorphine. ${ }^{12}$

Human obesity due to congenital, monogenic leptin deficiency is rare ${ }^{42}$ and leptin-deficient ob/ob mice do not emulate most cases of human obesity. The ob/ob mice, however, provide a valuable animal model with the potential to clarify the multiple functions of leptin. The $\mathrm{db} / \mathrm{db}$ mice produce leptin but fail to express the long-form of the leptin receptor. ${ }^{43,44}$ Studies by others have used DIO, ob/ob, and $\mathrm{db} / \mathrm{db}$ mice to gain insights into metabolic syndrome ${ }^{45}$ and type- 2 diabetes. ${ }^{46,47}$ To our knowledge, the present data provide the first evidence that leptin signaling alters the effects of buprenorphine on minute ventilation by reducing minute ventilation variability.

\section{Poincaré Analysis of Minute Ventilation Variability}

Comparing figure 3 with figs. 2, 4, and 5 illustrates the ability of Poincare plots to provide a nuanced visualization of respiratory variability. In the Methods section, the description of Poincaré as exploratory data analysis refers to an "attitude, a state of flexibility, a willingness to look for those things that we believe are not there, as well as those we believe to be there". 48 The present application of Poincare analysis demonstrates that buprenorphine significantly reduces minute ventilation variability. Figure 3 also makes clear that after saline administration, the mice with functional leptin systems ( $\mathrm{B} 6$ and $\mathrm{DIO}^{49}$ ) had significantly greater variability in minute ventilation than the mice with dysfunctional leptin transmission (ob/ob and $\mathrm{db} / \mathrm{db}$ ). Consequently, the decrease in minute ventilation variability caused by buprenorphine was greatest for B6 and DIO mice that express both leptin and functional leptin receptors. Statistical analyses showed that leptin status played a central role via its ordinal interaction with sex and injection of buprenorphine. This finding supports the interpretation that leptin dysfunction (ob/ob and $\mathrm{db} / \mathrm{db}$ ), rather than obesity in the presence of leptin (DIO), conferred the greatest risk for decreased minute ventilation variability (fig. 3 ). The present results are consistent with evidence that leptin status rather than obesity causes an impaired ventilatory response to hypercapnia in ob/ob mice..$^{50}$

\section{Limitations}

Potential limitations of the present study include the murine model, unknown mechanisms of leptin signaling, and the mathematics underlying the present discovery. The limitations of mice as models of human obesity ${ }^{51}$ and obesity-related diseases derive from evolutionary differences in gene expression between mouse and human. ${ }^{52}$ While acknowledging these limitations, the NIH considers the mouse as "the premier mammalian model system for genetic research" https://www.genome.gov/10005834/background-on-mouse-as-a-model- 
organism/. The genetics of human obesity reveal good homology with genotypes known to promote obesity in mice. ${ }^{53}$ Second, the mechanisms by which leptin, a protein produced by adipocytes, influences breathing remain unknown. ${ }^{24,25,50,54,55}$ It is clear, however, that leptin function is not limited to energy homeostasis. ${ }^{56}$ Leptin modulates neuronal excitability ${ }^{57}$ and long-standing evidence shows that leptin stimulates breathing. ${ }^{22,23}$ The present results should not be misinterpreted as indicating that leptin is the only adipocytederived molecule modulating the buprenorphine-induced collapse in minute ventilation variability. The potential involvement of additional cell signaling proteins is suggested by the fact that adipose tissue functions as an endocrine organ and secretes hundreds of different adipokines. ${ }^{58}$ Furthermore, inferring that only leptin from adipocytes modulates the effects of buprenorphine may be too simplistic in view of the discovery that leptin also is produced by parathyroid glands. ${ }^{59} \mathrm{~A}$ third potential limitation is interpreting and communicating time-domain data. The present study included Poincaré methods because the analyses (fig. 3) "correspond so conveniently to time domain summary statistics." 37 Strengths and limitations of Poincaré analysis and its numeric descriptors (figs. 4 and 5) have been reviewed in detail. ${ }^{30,60}$

\section{Conclusions}

The results show that buprenorphine causes a collapse in minute ventilation variability, with the greatest collapse occurring in mice that lack normal leptin signaling. The results are consistent with evidence that leptin signaling alters antinociceptive effects of buprenorphine.

${ }^{12}$ Respiratory variability is clinically relevant because such variability is an essential aspect of homeostasis (e.g., increasing tidal volume or respiratory rate) in response to challenges imposed by disease, obesity, surgical stress, and opiates. In cases where buprenorphine does cause respiratory depression, pharmacokinetic data make the cautionary point that buprenorphine-induced respiratory depression "outlasts the effects of naloxone-induced reversals from bolus injections". ${ }^{61}$ Thus, the present findings encourage future studies to characterize the time-course of the buprenorphine-induced decrease in respiratory variability. The novelty of the present findings is further illustrated by the fact that all previous clinical studies of the respiratory effects of buprenorphine have involved normal weight individuals. Maintaining ventilation within a normal range is key in the perioperative setting. However, that goal is complicated by the increasing number of obese patients and by patients who chronically use opiates or who are prescribed buprenorphine to manage their opiate use disorder. ${ }^{1}$ Poincare analysis of heart rate variability has a long record of diagnostic and prognostic success. The present results encourage future human studies to determine whether Poincaré plots have diagnostic or prognostic value relevant to respiratory depression caused by opiates.

\section{Acknowledgments}

We gratefully acknowledge support by the Beaman Endowed Professorship (HAB) and Robert H. Cole Endowed Professorship (RL).

Funding Statement: Supported by NIH grant HL65272, the Departments of Anesthesiology and Psychology, and grant from NeuroNET. 


\section{References}

1. Volkow ND, Collins FS. The role of science in addressing the opioid crisis. N Engl J Med. 2017; 377:391-394. [PubMed: 28564549]

2. Swinburn BA, Sacks G, Hall KD, McPherson K, Finegood DT, Moodie ML, Gortmaker SL. The global obesity pandemic: shaped by global drivers and local environments. Lancet. 2011; 378:804414. [PubMed: 21872749]

3. Cronin A, Keifer JC, Baghdoyan HA, Lydic R. Opioid inhibition of rapid eye movement sleep by a specific mu receptor agonist. Br J Anaesth. 1995; 74:188-192. [PubMed: 7696070]

4. Osman NI, Baghdoyan HA, Lydic R. Morphine inhibits acetylcholine release in rat prefrontal cortex when delivered systemically or by microdialysis to basal forebrain. Anesthesiology. 2005; 103:779787. [PubMed: 16192770]

5. Lydic, R., Baghdoyan, HA. Neurochemical mechanisms mediating opioid-induced REM sleep disruption, Sleep and Pain. Lavigne, G.Sessle, BJ.Choinière, M., Soja, PJ., editors. Seattle, WA: International Association for the Study of Pain (IASP) Press; 2007. p. 99-122.

6. Hambrecht VS, Vlisides PE, Row BW, Gozal D, Baghdoyan HA, Lydic R. Hypoxia modulates cholinergic but not opioid activation of $\mathrm{G}$ proteins in rat hippocampus. Hippocampus. 2007; 17:934-942. [PubMed: 17598161]

7. Wang W, Baghdoyan HA, Lydic R. Leptin replacement restores supraspinal cholinergic antinociception in leptin-deficient obese mice. J Pain. 2009; 10:836-843. [PubMed: 19380255]

8. Nelson AM, Battersby AS, Baghdoyan HA, Lydic R. Opioid-induced decreases in rat brain adenosine levels are reversed by inhibiting adenosine deaminase. Anesthesiology. 2009; 111:132733. [PubMed: 19934879]

9. Gauthier EA, Guzick SE, Brummett CM, Baghdoyan HA, Lydic R. Buprenorphine disrupts sleep and decreases adenosine concentrations in sleep-regulating brain regions of Sprague Dawley rat. Anesthesiology. 2011; 115:838-843.

10. Watson SL, Watson CJ, Baghdoyan HA, Lydic R. Adenosine A1 receptors in mouse pontine reticular formation modulate nociception only in the presence of systemic leptin. Neuroscience. 2014; 275:531-539. [PubMed: 24976513]

11. Lydic, R., Keifer, JC., Baghdoyan, HA., Craft, R., Angel, C. Opiate action on sleep and breathing, Principles and Practice of Sleep Medicine. 6. Kryger, MH.Roth, T., Dement, WC., editors. New York: Elsevier; 2017. p. 250-259.

12. Glovak ZT, Mihalko S, Baghdoyan HA, Lydic R. Leptin status alters buprenorphine-induced antinociception in obese mice with dysfunctional leptin receptors. Neurosci Letts. 2017; 660:29_ 33. [PubMed: 28893589]

13. Dahan A, Sarton E, Teppema L, Olievier C. Sex-related differences in the influence of morphine on ventilatory control in humans. Anesthesiology. 1998; 88:903-913. [PubMed: 9579498]

14. Behan M, Zabka AG, Thomas CF, Mitchell GS. Sex steroid hormones and the neural control of breathing. Respir Physiol Neurobiol. 2003; 136:249-263. [PubMed: 12853015]

15. Sarton E, Teppema L, Dahan A. Sex differences in morphine-induced ventilatory depression reside within the peripheral chemoreflex loop. Anesthesiology. 1999; 90:1329-1338. [PubMed: 10319781]

16. Domi R, Laho H. Anesthetic challenges in the obese patient. J Anesth. 2012; 26:758-765. [PubMed: 22562644]

17. Bryson EO. The perioperative management of patients maintained on medications used to manage opioid addiction. Curr Opin Anesthesiol. 2014; 27:359-364.

18. Schuckit MA. Treatment of opioid-use disorders. N Engl J Med. 2016; 375:357-368. [PubMed: 27464203]

19. Sarton E, Olofsen E, Romberg R, den Hartigh J, Kest B, Nieuwenhuijs D, Burm A, Teppema L, Dahan A. Sex differences in morphine analgesia: an experimental study in healthy volunteers. Anesthesiology. 2000; 93:1245-1254. [PubMed: 11046213]

20. Klein SL, Schiebinger L, Sfefanick ML, Cahill L, Danska J, de Vries GJ, Kibbe MR, MMM, Mogil JS, Woodruff TK, Zucker I. Sex inclusion in basic research drives discovery. PNAS. 2015; 112:5257-5258. [PubMed: 25902532] 
21. Shansky RM, Woolley CS. Considering sex as a biological variable will be valuable for neuroscientific research. J Neurosci. 2016; 36:11817-11822. [PubMed: 27881768]

22. Tankersley C, Kleeberger S, Russ B, Schwartz A, Smith P. Modified control of breathing in genetically obese (ob/ob) mice. J Appl Physiol. 1996; 81:716-723. [PubMed: 8872638]

23. O'Donnell CP, Schaub CD, Haines AS, Berkowitz DE, Tankersley CG, Schwartz AR, Smith PL. Leptin prevents respiratory depression in obesity. Am J Respir Crit Care Med. 1999; 159:14771484. [PubMed: 10228114]

24. Malli F, Papaioannou AI, Gourgoulianis KI, Daniil Z. The role of leptin in the respiratory system: an overview. Resp Res. 2010; 11:152-167.

25. Yao Q, Pho H, Kirkness JP, Ladenheim EE, Bi S, Moran TH, Fuller DD, Schwartz A, Polotsky VY. Localizing effects of leptin on upper airway and respiratory control during sleep. Sleep. 2016; 39:1097-1106. [PubMed: 26951402]

26. Lufty K, Eitan S, Bryant CD, Yang YC, Saliminejad N, Walwyn W, Kieffer BL, Takeshima H, Carroll FI, Maidment NT, Evans CJ. Buprenorphine-induced antinociception is mediated by muopioid receptors and compromised by concomitant activation of opioid receptor-like receptors. $\mathbf{J}$ Neurosci. 2003; 23:10331-10337. [PubMed: 14614092]

27. Strohl KP, Thomas AJ, St Jean P, Schlenker EH, Koletsky RJ, Schork NJ. Ventilation and metabolism among rat strains. J Appl Physiol. 1997; 82:317-323. [PubMed: 9029232]

28. Icaza EE, Huang X, Fu Y, Neubig RR, Baghdoyan HA, Lydic R. Isoflurane-induced changes in righting response and breathing are modulated by RGS proteins. Anesth Analg. 2009; 109:15001505. [PubMed: 19843788]

29. Filbey WA, Sanford DT, Baghdoyan HA, Koch LG, Britton SL, Lydic R. Eszopiclone and dexmedetomidine depress ventilation in obese rats with features of metabolic syndrome. Sleep. 2014; 37:871-880. [PubMed: 24790265]

30. Khandoker, AH., Karmakar, CK., Brennan, M., Voss, A., Palaniswami, M. Poincaré Plot Methods for Heart Rate Variability Analysis. New York: Springer; 2013.

31. Xia Y, Gao Q, Lu Y, Ye Q. A novel approach for analysis of altered gait variability in amyotrophic lateral sclerosis. Med Biol Eng Comput. 2016; 54:1399-1408. [PubMed: 26518306]

32. Brignol A, Al-ani T, Drouot X. Phase space and power spectral approaches for EEG-based automatic sleep-wake classification in humans: A comparative study using short and standard epoch lengths. Comput Methods Programs Biomed. 2013; 109:227-238. [PubMed: 23164523]

33. Kubickova A, Kozumplik J, Novakova Z, Plachy M, Jurak P, Lipoldova J. Heart rate variability analysed by Poincaré plot in patients with metabolic syndrome. J Electrocardiol. 2016; 49:23-28. [PubMed: 26639443]

34. Bien M-Y, Hseu S-S, Kuo B, I-TY-TL, Wang J-H, Kou YR. Breathing pattern variability: a weaning predictor in postoperative patients recovering from systemic inflammatory response syndrome. Intensive Care Med. 2004; 30:241-247. [PubMed: 14647889]

35. Bolaños, JD., Vallverdú, M., Caminal, P., Valencia, DF., Borrat, X., Gambús, PL., Valencia, JF. Assessment of sedation-analgesia by means of Poincaré analysis of the electroencephalogram, Engineering in Medicine and Biology Society (EMBC). 2016 IEEE 38th Annual International Conference of the, IEEE; 2016; p. 6425-6428.

36. Hayashi K, Yamada T, Sawa T. Comparative study of Poincare plot analysis using short electroencephalogram signals during anaesthesia with spectral edge frequency 95 and bispectral index. Anaesthesia. 2015; 70:310-317. [PubMed: 25271796]

37. Brennan M, Palaniswami M, Kamen P. Do existing measures of Poincaré plot geometry reflect nonlinear features of heart rate variability? IEEE Trans Biomed Eng. 2001; 48:1342-1347.

[PubMed: 11686633]

38. Conway B, Rene A. Obesity as a disease: no lightweight matter. Obesity Rev. 2004; 5:145-151.

39. Fryhofer, SA., Martin, DW. AMA Resolution 115-A-12 Obesity should be considered a chronic medical disease state. AMA REPORT OF THE COUNCIL ON SCIENCE AND PUBLIC HEALTH; 2012. https://www.ama-assn.org/sites/default/files/media-browser/public/about-ama/ councils/CouncilReports/council-on-science-public-health/a13csaph3.pdf 
40. Lee LA, Caplan RA, Stephens LS, Posner KL, Terman GW, Voepel-Lewis T, Domino KB. Postoperative opioid-induced respiratory depression: A closed claims analysis. Anesthesiology. 2015; 122:659-665. [PubMed: 25536092]

41. Bogue MA, Grubb SC. The mouse phenome project. Genetica. 2004; 122:71-74. [PubMed: 15619963]

42. Farooqi IS, Matarese G, Lord GM, Keogh JM, Lawrence E, Agwu C, Sanna V, Jebb SA, Perna F, Fontana S, Lechler RI, DePaoli AM, O'Rahilly S. Beneficial effects of leptin on obesity, T cell hyporesponsiveness, and neuroendocrine/metabolic dysfunction of human congenital leptin deficiency. J Clin Invest. 2002; 110:1093-1103. [PubMed: 12393845]

43. Bjøbæk C, Uotani S, da Silva B, Flier S. Divergent signaling capacaties of the long and short isoforms of the leptin receptor. J Biol Chem. 1997; 272:32686-32695. [PubMed: 9405487]

44. Banks AS, Davis SM, Bates SH, Myers MG. Activation of downstream signals by the long form of the leptin receptor. J Biol Chem. 2000; 275:14563-14572. [PubMed: 10799542]

45. Sinasac DS, Riordan JD, Spiezio SH, Yandell BS, Croniger CM, Nadeau JH. Genetic control of obesity, glucose homeostasis, dyslipidemia and fatty liver in a mouse model of diet-induced metabolic syndrome. Int J Obes. 2016; 40:346-355.

46. Sullivan KA, Hayes JM, Wiggin TD, Bakus C, Oh SS, Lentz SI, Brosius F, Feldman EL. Mouse models of diabetic neuropathy. Neurobiol Dis. 2007; 28:276-285. [PubMed: 17804249]

47. O'Brien PD, Sakowski SA, Feldman EL. Mouse models of diabetic neuropathy. ILAR J. 2014; 54:259-272. [PubMed: 24615439]

48. Tukey, JW. Exploratory Data Analysis. Reading, PA: Addison-Wesley; 1977.

49. Ottaway N, Mahbod P, Bivero B, Norman LA, Gertler A, D’Alessio DA, Perez-Tilve D. Dietinduced obese mice retain endogenous leptin action. Cell Metabolism. 2015; 21:877-882. [PubMed: 25980347]

50. Bassi M, Furuya WI, Zoccal DB, Menani JV, Colombari DSA, Mulkey DK, Columbari E. Facilitation of breathing by leptin effects in the central nervous system. J Physiol. 2015; 594:16171625. [PubMed: 26095748]

51. Nilsson C, Raun K, Yan F-F, Larsen MO, Tang-Christensen M. Laboratory animals as surrogate models of human obesity. Acta Pharmacologica Sinica. 2012; 33:173-181. [PubMed: 22301857]

52. Perlman RL. Mouse models of disease: An evolutionary perspective. Evol Med Public Health. 2016; doi: 10.1093/emph/eow014:170-176

53. Farooqi IS, O'Rahilly S. Genetics of obesity in humans. Endocrine Rev. 2006; 27:710-718. [PubMed: 17122358]

54. Bassi M, Giusti H, Leite CM, Anselmo-Franci A, do Carmo JM, da Silva AA, Hall JE, Colombari E, Glass JI. Central leptin replacement enhances chemorespiratory responses in leptin-deficient mice independent of changes in body weight. Pflugers Arch - Eur J Physiol. 2012; 464:145-153. [PubMed: 22585210]

55. Pho H, Hernandez AB, Arias RS, Leitner EB, Van Kooten S, Kirkness JP, Schneider H, Smith PL, Polotsky VY, Schwartz AR. The effect of leptin replacement on sleep-disordered breathing in the leptin-deficient ob/ob mouse. J Appl Physiol. 2016; 120:78-86. [PubMed: 26472867]

56. Friedman JM, Mantzoros CS. 20 years of leptin: From the discovery of the leptin gene to leptin in our therapeutic armamentarium. Metab Clin Exp. 2015; 64:1-4. [PubMed: 25497341]

57. Sutton AK, Myers MG, Olson DP. The role of PCH circuits in leptin action and energy balance. Annu Rev Physiol. 2016; 78:207-21. [PubMed: 26863324]

58. Kunath A, Klöting N. Adipocyte biology and obesity-mediated adipose tissue remodeling. Obesity Med. 2016; 4:15-20.

59. Hoang D, Broer N, Sosa JA, Abitbol N, Yao X, Li F, Rivera-Molina F, Toomre DK, Roman SA, Sue G, Kim S, Li AY, Callender GG, Simpson C, Narayan D. Leptin is produced by parathyroid glands and stimulates parathyroid hormone secretion. J Biol Chem. 2017

60. Karmakar CK, Khandoker AH, Gubbi J, Palaniswami M. Defining asymmetry in heart rate variability signals using a Poincaré plot. Physiol Meas. 2009; 30:1227-1240. [PubMed: 19812453]

61. Dahan A, Aarts L, Smith TW. Incidence, reversal, and prevention of opioid-induced respiratory depression. Anesthesiology. 2010; 112:226-238. [PubMed: 20010421] 


\section{Summary Statement}

Buprenorphine collapses respiratory variability in obese mice with altered leptin signaling. 


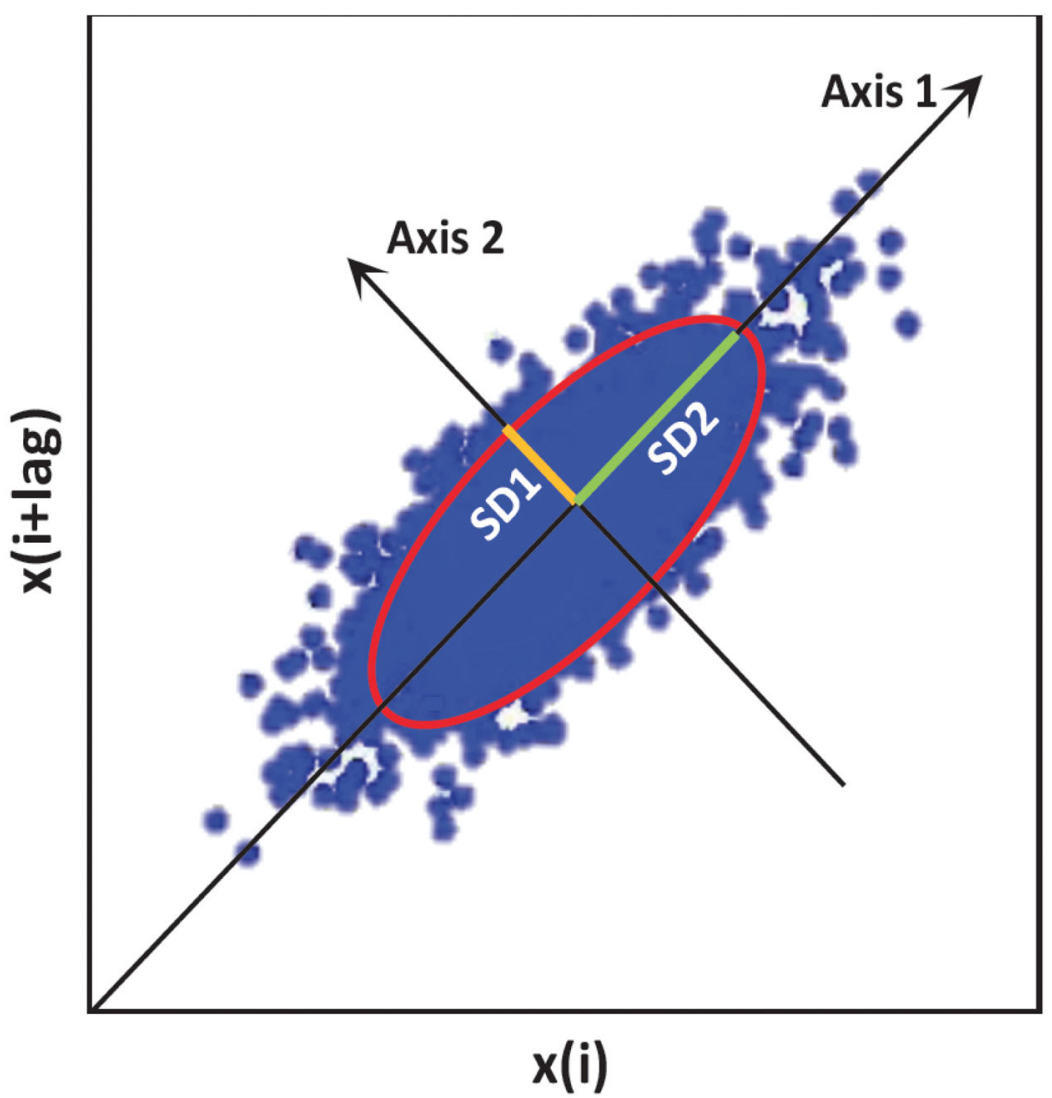

Fig. 1.

Poincaré plot illustrating a distribution of points representing heart rate RR interval. Similar plots can be created for any biological rhythm. For example, breath-to-breath intervals x (i), are plotted versus the delay time between breaths, $x(i+l a g)$. The descriptors SD1 and SD2 are Poincaré metrics describing the resulting dispersion of points. SD1 (yellow line along Axis 2) is the standard deviation of successive differences between sequential events, such as breaths. SD1 is a measure of short-term (e.g., breath-to-breath) variability and is illustrated as the standard deviation of the points that are perpendicular to the line of identify. SD2 (green line along Axis 1) quantifies the overall (long-term) variability during the measurement period as the distribution of points along the line $\mathrm{x}=\mathrm{y}$. Poincaré plots are widely applicable for characterizing clinically relevant biological rhythms. Figure reprinted from $^{35}$ with permission. 


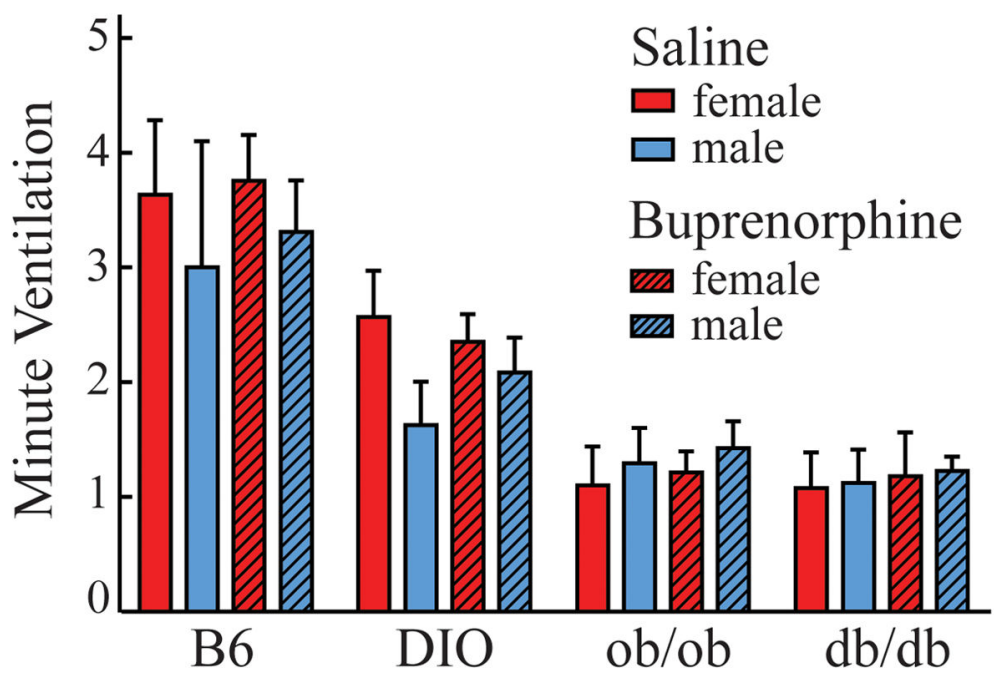

Fig. 2.

Minute ventilation varied significantly among congenic mice. Mice with leptin dysfunction (ob/ob and $\mathrm{db} / \mathrm{db}$ ) had the lowest minute ventilation (mean + standard deviation $\mathrm{mL} / \mathrm{min} / \mathrm{g}$ body weight). Abbreviations: C57BL/6J (B6), B6 with Diet-Induced Obesity (DIO), B6.CgLep $^{\mathrm{ob}} / \mathrm{J}$ (ob/ob), B6.BKS(D)-Lepr ${ }^{\mathrm{db} / J}(\mathrm{db} / \mathrm{db})$. 

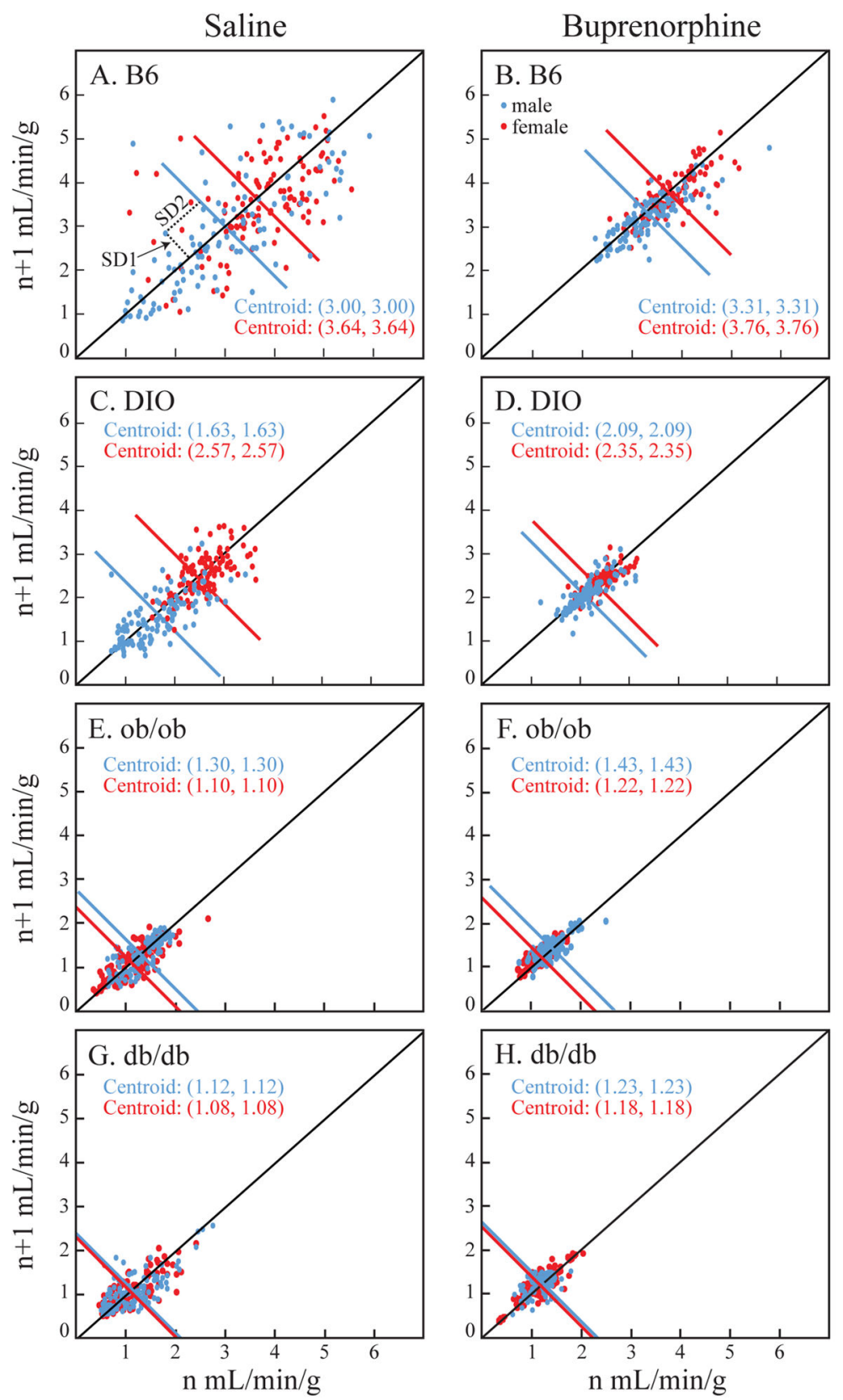

Fig. 3.

Poincarè plots of buprenorphine-induced decrease in minute ventilation variability. Each frame plots data from 10 male (blue dots) and 10 female (red dots) mice for $1 \mathrm{~h}$ after injection of saline (A, C, E, G) or an antinociceptive dose of buprenorphine $(0.3 \mathrm{mg} / \mathrm{kg}$; B, $\mathrm{D}, \mathrm{F}, \mathrm{H})$. Also shown in black for each frame is the line of identity $(\mathrm{x}=\mathrm{y})$ and coordinates $(\mathrm{x}, \mathrm{y})$ of the average position of all data points (centroid) for males (blue font) and females (red font). The red and blue lines placed perpendicular to the line of identity mark the centroid for males and females, respectively. The dotted lines in A indicate how short-term variability (SD1) and long-term variability (SD2) are calculated for a single data point. 
C57BL/6J (B6), B6 with Diet-Induced Obesity (DIO), B6.Cg-Lep ${ }^{\mathrm{ob} / J}$ (ob/ob), B6.BKS(D)Lepr $^{\mathrm{db} / J}(\mathrm{db} / \mathrm{db})$. 


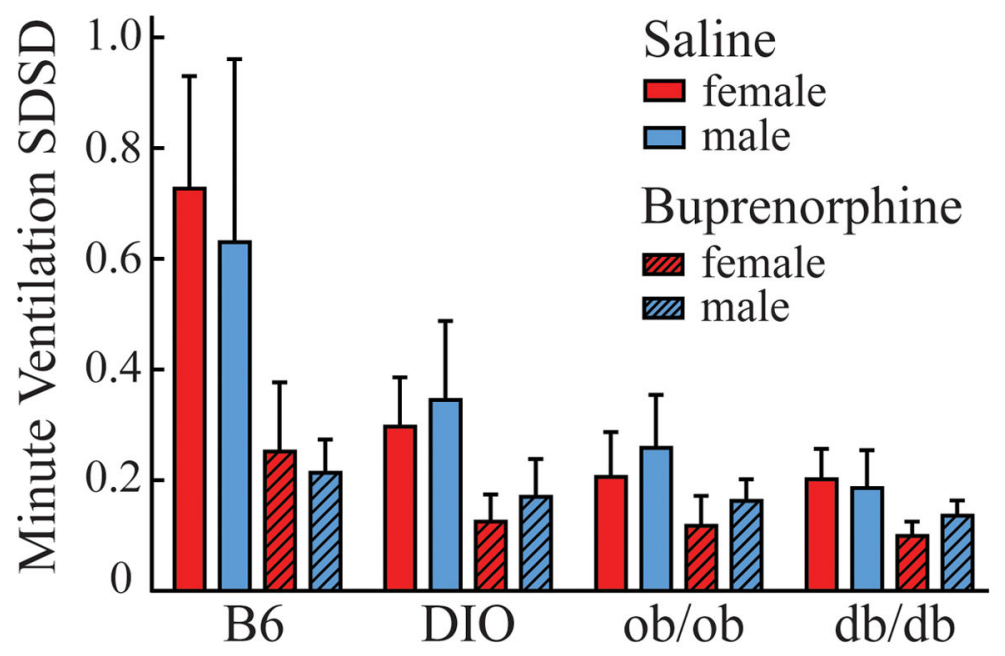

Fig. 4.

Standard deviation of successive differences in breath-to-breath intervals (SDSD) indicates short-term variability, as does SD1 in fig. 3. Histograms plot the mean + standard deviation of SDSD for mouse line by sex and injection condition (saline $v s$. buprenorphine). In all mouse lines, buprenorphine caused a collapse in breath-to-breath variability of minute ventilation. C57BL/6J (B6), B6 with Diet-Induced Obesity (DIO), B6.Cg-Lep ${ }^{\mathrm{ob}} / \mathrm{J}$ (ob/ob), B6.BKS(D)-Lepr ${ }^{\mathrm{db}} / \mathrm{J}(\mathrm{db} / \mathrm{db})$. 


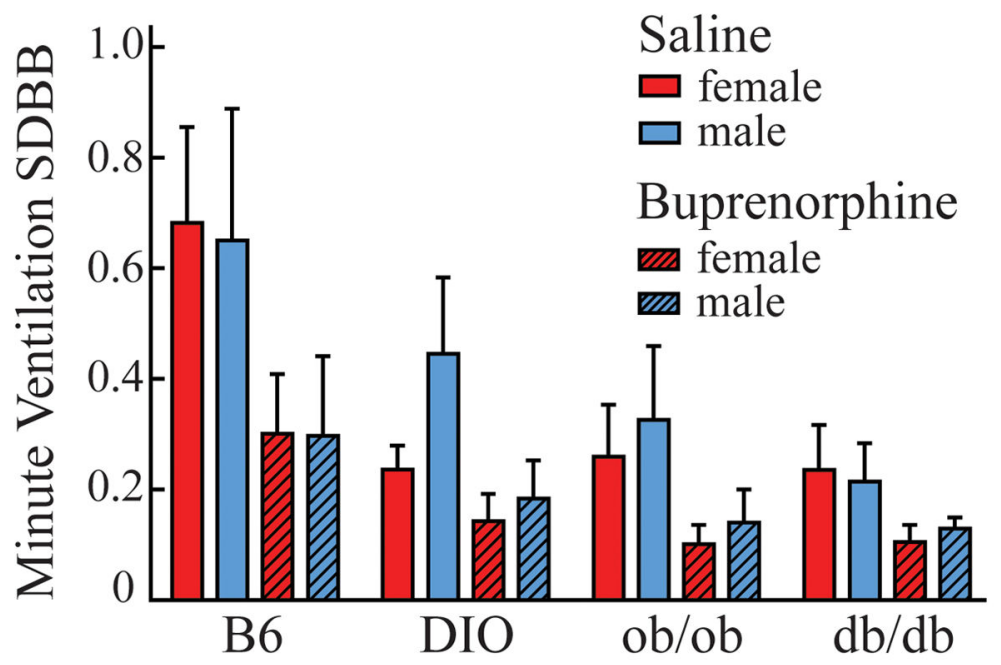

Fig. 5.

Buprenorphine decreased overall (long-term) variability of minute ventilation. Changes in variability of the standard deviation of breath-to-breath intervals (SDBB) are plotted as mean + standard deviation. These histograms correspond to the variability along the line $\mathrm{x}=\mathrm{y}$ in fig. 3. C57BL/6J (B6), B6 with Diet-Induced Obesity (DIO), B6.Cg-Lep ${ }^{\mathrm{ob}} / \mathrm{J}$ (ob/ob), B6.BKS(D)-Lepr ${ }^{\mathrm{db} / J}$ (db/db). 

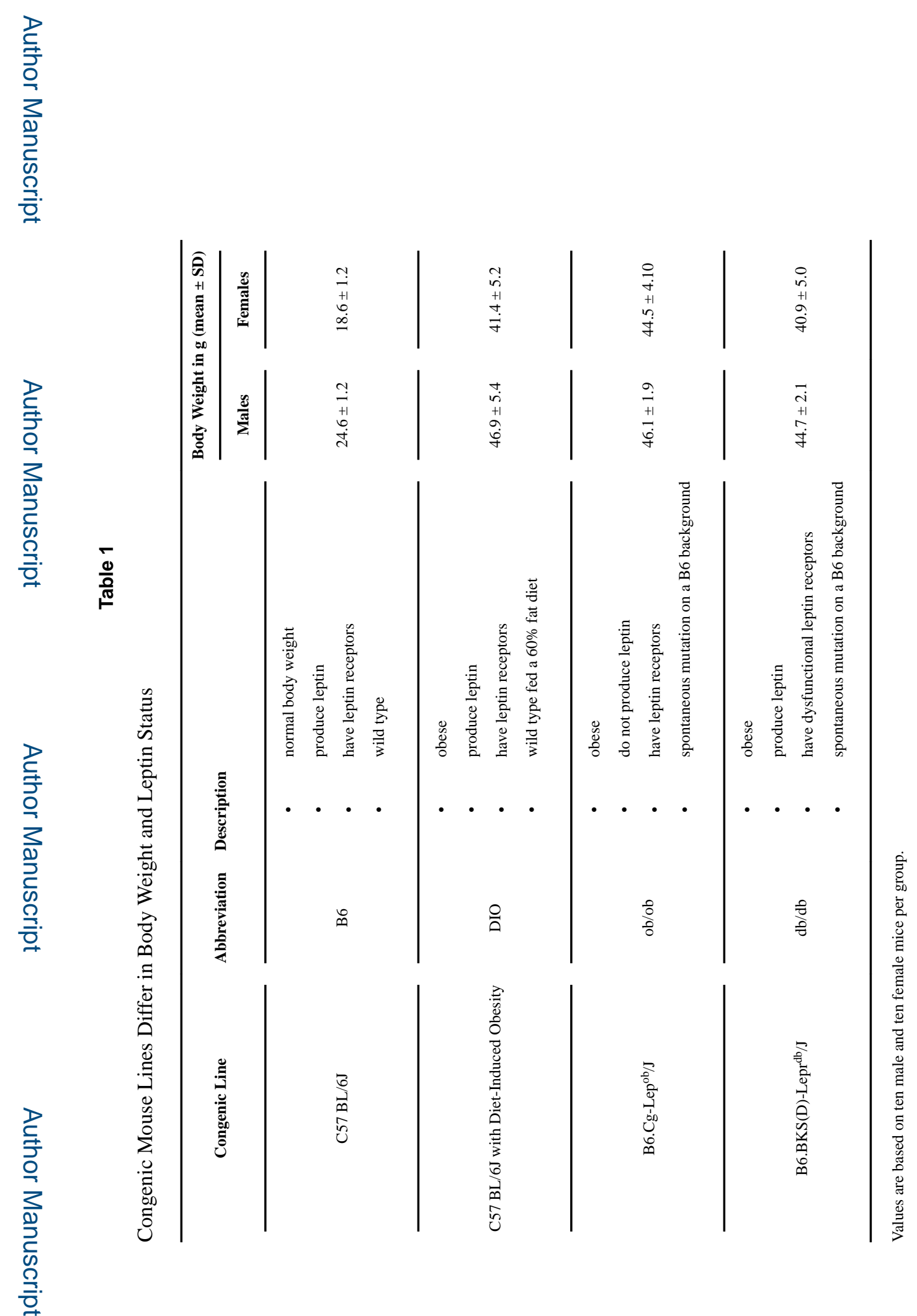

Anesthesiology. Author manuscript; available in PMC 2019 May 01. 